\title{
A política externa brasileira do governo Lula da Silva (2003-2010) nas páginas de CartaCapital e Veja: um estudo comparativo ${ }^{1}$
}

The Brazilian foreign policy of Lula da Silva government (2003-2010) in the pages of CartaCapital and Veja: a comparative study

La política exterior brasileña del gobierno Lula da Silva (2003-2010) en las páginas de CartaCapital y Veja: un estudio comparativo

DOI: https://doi.org/10.1590/1809-58442021110

\section{Túlio Sérgio Henriques Ferreira ${ }^{1}$}

http://orcid.org/0000-0003-2561-2700

Ester Almeida Carneiro da Cunha ${ }^{2}$

https://orcid.org/0000-0002-9487-6833

${ }^{1}$ (Universidade Federal da Paraíba, Departamento de Relações Internacionais, Programa de Pós-Graduação em Ciência Política e Relações Internacionais. João Pessoa - PB, Brasil).

${ }^{2}$ (Universidade de São Paulo, Instituto de Relações Internacionais, Programa de Pós-Graduação em Relações Internacionais. São Paulo - SP, Brasil).

\section{Resumo}

O artigo compara o tratamento da Política Externa Brasileira (PEB) nos semanários Veja e CartaCapital durante os dois mandatos presidenciais de Luís Inácio Lula da Silva (2003-2010). Analisou-se, qualitativa e quantitativamente, cinco grupos temáticos relacionados à PEB com o intuito de contribuir para adensar os estudos sobre meios de comunicação e política externa no Brasil. Assim, em consonância com as abordagens da Análise de Política Externa (APE) e considerando a mútua influência entre mídia, opinião pública e processos políticos, ressaltou-se o papel dos meios de comunicação como ator político. Demonstrou-se, assim, a diferença no tratamento do tema nos dois semanários, testando-se a hipótese de que a divergência explícita das linhas editoriais resultaria em contrastes na cobertura do assunto.

Palavras-chave: Política Externa Brasileira. Meios de Comunicação. Veja. CartaCapital. Governo Lula da Silva.

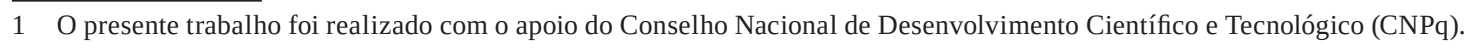




\begin{abstract}
The article compares the treatment of Brazilian Foreign Policy (PEB) in Veja and CartaCapital during two presidential terms of Luís Inácio Lula da Silva (2003-2010). Five thematic groups related to PEB were analyzed qualitative and quantitatively in order to contribute to the study of media and foreign policy in Brazil. Thus, in line with the Foreign Policy Analysis (APE) approaches and considering the mutual influence between media, public opinion and political processes, the role of the media as a political actor was emphasized. The difference in the treatment of the topic in the two weekly newspapers was demonstrated, while testing the hypothesis that the explicit divergence of editorial lines would result in contrasts in the coverage of the subject.
\end{abstract}

Keywords: Brazilian Foreign Policy. Media. Veja. CartaCapital. Lula da Silva Government.

\title{
Resumen
}

El artículo compara el tratamiento de la política exterior brasileña (PEB) en los semanarios Veja y CartaCapital durante los dos mandatos presidenciales de Luis Inacio Lula da Silva (2003-2010). Se analizó, cualitativa y cuantitativamente, cinco grupos temáticos relacionados a la PEB con el propósito de contribuir a adensar los estudios sobre medios de comunicación y política exterior en Brasil. Así, en consonancia con los enfoques del Análisis de Política Exterior (APE) y considerando la mutua influencia entre medios, opinión pública y procesos políticos, se resaltó el papel de los medios de comunicación como actor político. Se demostró así la diferencia en el tratamiento del tema en los dos semanarios, probandose la hipótesis de que la divergencia explícita de las líneas editoriales resultaría en contrastes en la cobertura del asunto.

Palabras clave: Política Exterior del Brasil. Medios de comunicación. Veja. CartaCapital. Gobierno Lula da Silva.

\section{Introdução}

‘Diplomacia sem resultado’. Assim a Revista Veja descrevia a Política Exterior do governo Lula da Silva em 2009. CartaCapital, no mesmo ano, publicava que as 'missões empresariais de Lula no exterior rendem bons negócios’. Revelara-se evidente a divergência nas reportagens de dois relevantes semanários brasileiros daquele período. Tal discrepância animou este estudo, que versará sobre a cobertura jornalística da Política Externa Brasileira (PEB) dos mandatos de Lula da Silva (2003-2010) nas páginas de Veja e CartaCapital.

Os meios de comunicação, que no início do século XX, eram desprezados pelos policy makers que entendiam ser a diplomacia incompreensível às 'pessoas comuns', passam a ser, paulatinamente, valorizados no processo político. Herman e Chomsky (2002, p. 1) defendem que os meios de 'comunicação de massa' servem para “divertir, entreter, informar e inculcar os indivíduos com os valores, crenças e códigos de comportamento que os integrem nas estruturas institucionais da sociedade mais ampla”. Nogueira (2012, p. 118), por sua vez, argumenta que "os meios de comunicação de massa podem ser entendidos como importantes agentes sociais envolvidos em processos de construções cognitivas coletivas, 
uma vez que veiculam em larga escala discursos interessados”. Portanto, dominar os meios de transmissão das informações continua a ser fator relevante na aquisição e legitimação do poder (KEOHANE; NYE, 1977).

Com o crescente processo de flexibilização das tradicionais fronteiras entre os Estados, é mais fácil o acesso à informação e o intercâmbio de ideias entre nacionalidades distintas. Para Lessa e Gavião (2001), este fenômeno comunicacional provê acesso mais intenso aos temas internacionais, fato que pode repercutir na política externa dos países. Neste sentido, Robinson (2008) advoga que a relação sobre opinião pública e política externa torna-se crucial ao observar-se a centralidade dos diversos meios de comunicação na produção, transmissão e aquisição da informação em todas as áreas da atividade dos homens. No entanto, estudos mais detalhados sobre a relação entre meios de comunicação e política exterior ainda são escassos, principalmente no Brasil, fato que se manifesta na minguada literatura sobre o tema e na carência de dados que possam embasar pesquisas mais aprofundadas.

Com o intuito de contribuir para adensar os estudos sobre mídia e política externa, o presente trabalho analisa a cobertura da PEB nos governos de Luiz Inácio Lula da Silva (2003-2010) em dois semanários do Brasil. Faz-se abordagem qualitativa e quantitativa do tratamento da PEB nas páginas de CartaCapital e Veja. Tendo-se em conta a expressa divergência editorial das duas publicações, estabelece-se como hipótese inicial a existência de distinções notáveis na apresentação qualitativa do tema, esperando-se maior teor negativo em Veja do que em CartaCapital. Portanto, busca-se demonstrar quantitativa e qualitativamente o viés editorial expresso nas publicações.

Observe-se que não se pretende, neste estudo, demonstrar a influência dos referidos semanários brasileiros na formulação da Política Exterior Brasileira, uma vez que estabelecer tal causalidade fugiria ao escopo do estudo. De fato, até o momento, não existe concordância sobre como quantificar a influência ou a relação da opinião pública e da mídia, como um ator imaterial, na formulação das políticas de Estado, ainda mais na formulação de política externa ${ }^{2}$. No entanto, tendo em vista o debate referente à mútua dependência entre mídia, opinião pública e processos políticos, pode-se indicar que tal variável não poderia ser desprezada no jogo do processo decisório ${ }^{3}$. Para tanto, este artigo, além da introdução e conclusão, possui três partes breves e uma mais alentada de apresentação de dados. A primeira seção apresentará o debate teórico relativo à opinião pública e aos meios de comunicação no que tange às Relações Internacionais e ao subcampo da Análise de Política Externa. Também serão explicitadas as balizas metodológicas. A segunda descreve brevemente a estrutura de comunicação do Brasil. A terceira localiza os semanários em análise no conjunto da imprensa escrita brasileira. Por fim, na quarta seção, deliberadamente mais extensa, farse-á a apresentação de dados e a comparação quantitativa e qualitativa do tratamento da Política Externa nas páginas dos dois semanários brasileiros, destacando-se quatro grandes

2 Para estudos que abordam o debate sobre a influência ver: Robinson (2001), Naveh (2002), Hill (2003), Soroka (2003) e Robinson (2008).

3 Para maiores detalhes sobre o debate ver: Baum e Potter (2008, 2019). 
temáticas: 1) os principais temas das reportagens; 2) a segmentação temática dos artigos; 3) viés das publicações; e 4) a figura presidencial.

As considerações finais serão reservadas para a confirmação ou refutação da principal hipótese do trabalho, assim como para a sistematização dos dados encontrados no decorrer da investigação.

\section{Teoria e metodologia}

A despeito da importância dos meios de comunicação e da opinião pública como variáveis analíticas, ainda não há consenso sobre a influência de tais variáveis na política externa dos países. (HILL, 2003, ROBINSON, 2008, MARIANUCCI, 2009, NOGUEIRA, 2012). Entretanto, demonstra-se consensual considerar os meios de comunicação como partícipes do processo social de produção e veiculação das informações. O subcampo da Análise de Política Externa (APE) terá grande contribuição analítica para tal debate ao centrar parte de suas preocupações no entendimento do processo decisório. Assim, sobreleva-se as considerações entre os meios de comunicação e a opinião pública na crescente literatura que analisa o impacto dos grupos societários no processo decisório da política exterior (HUDSON, 2005). Assim, estando enredados na estrutura socioeconômica, tais meios não devem ser considerados neutros ou desinteressados em sua ação. (HALLIN, 1986, HERMAN; CHOMSKY, 1988).

Burity (2013) argumenta que, a despeito do debate sobre a separação da mídia e do Estado, este tem demonstrado querer instrumentalizar o uso de tais meios para atingir seus objetivos. Assim, observa-se jogo complexo na relação entre Estado e os meios de comunicação em âmbito doméstico e internacional. Coincidindo com esse pensamento, Hill (2003, p. 73) aborda tal temática considerando que "na era da televisão, os meios de comunicação parecem reis. Eles parecem ser a chave para influenciar a opinião pública, e eles têm o ouvido e o olho do governo”.

Nesse sentido, pode-se considerar a importância dos meios de comunicação como atores do jogo político, por possuírem influência sobre a opinião pública e uma relação de proximidade com o governo. Neste processo, conclui-se que a mídia tem papel de gatekeepers da informação. Segundo Naveh (2002), a mídia não atua apenas transmitindo as informações, em um sistema de input (antes das decisões), mas faz parte do sistema de output. Assim, a mídia é um componente do processo de tomada de decisão, atuando como canal de informação e influente na formulação de políticas. Contraditoriamente, Cohen (1967) demonstra ser pequeno o espaço reservado às notícias sobre política exterior na mídia imprensa nos EUA no momento de sua pesquisa.

No Brasil, percebe-se incipiente produção nesta temática devido ao início relativamente tardio de tais abordagens na academia brasileira e, consequentemente, à ainda baixa coleta de dados que possam dar embasamento analítico ao assunto. As pesquisas costumam focar sua análise na posição de importância da mídia e seus efeitos na sociedade. 
O presente trabalho, além de analisar de modo geral os meios de comunicação no Brasil, tem como objetivo principal demonstrar a abordagem editorial de dois semanários brasileiros no que tange à PEB nas duas gestões Lula da Silva (2003-2010). Neste sentido, foi feita leitura sistemática de todos os artigos publicados em Veja e CartaCapital entre os anos de 2003 e 2010 que tratavam da PEB. Para a seleção do universo a ser analisado, além dos termos Política Exterior e Política Externa Brasileira, também foram incorporados termos correlatos como Política Internacional, Comércio Exterior, Negociação Internacional e assuntos correlatos que explicitassem o vínculo com a PEB. Após a seleção e coleta do universo de análise (a ser detalhado na quarta seção) e leitura sistemática, foram feitas as análises qualitativas e quantitativas no sentido de identificar eventuais divergências e convergências com as hipóteses anunciadas.

\section{Imprensa brasileira}

Radenovic (2006) ensina que a comunicação em massa se populariza no século XX devido à evolução dos meios para a transmissão da informação e ao avanço tecnológico, que permitem alcançar quantidades inéditas de destinatários. Inicialmente, os meios de comunicação eram considerados transmissores uniformes e restritos da informação. Pouco diversos ou de curto alcance, entregavam a todos a mesma informação. Com a 'mídia de massa’ as pessoas puderam ‘escolher’ os conteúdos a que teriam acesso (SHAW, 1979).

A partir dos anos 1970, a comunicação de massa nos EUA se modificou e começou a tomar a forma de conglomerados, devido a grandes fusões (BURITY, 2013). O Brasil viveu, a despeito de suas particularidades, situação parecida, com a conformação de conglomerados que comandam a produção e transmissão de informação. Entre os últimos anos do governo militar (1964-1985) e o período inicial da redemocratização (fim dos anos 1980 e início dos anos 1990), foram entabulados debates sobre o papel da mídia e sua influência nas políticas públicas. A Constituição de 1988 (CF88) e o novo ambiente democrático fizeram com que houvesse crescente participação de parcelas da sociedade civil nos assuntos políticos. Essas mudanças estruturais em curso, junto com o constante avanço tecnológico e evolução dos meios de comunicação, sobrelevaram a temática no fim do século XX. No que tange ao tema em análise, seria “justo assumir que a década de 1990 representou uma grande mudança na relação entre mídia de massas, opinião pública, e política externa” (CASARÕES, 2012, p. 212).

Analisando as características gerais dos meios de comunicação no Brasil, pode-se perceber alguns aspectos peculiares ao mercado de mídia do país. O primeiro ponto a ser observado é o surgimento tardio da indústria jornalística brasileira. Como colônia portuguesa, o primeiro jornal impresso em solo brasileiro foi a Gazeta do Rio de Janeiro em 1808. E a imprensa escrita no Brasil só ganhou estrutura comercial na virada do século XIX. É nesse período que surgem os grandes jornais de circulação nacional que dão origem à chamada “grande imprensa” no eixo Rio-São Paulo. (SODRÉ, 1999). 
A partir de 1930, o Brasil assiste rápida e constante expansão de seus meios de comunicação. Dois fatos devem ser destacados: “a formação dos Diários Associados, que tem início na década de 1920 e atinge seu ápice no final dos anos 1950, e a da Rede Globo, após o golpe de 1964” (MIGUEL, 2000, p. 195). Entretanto, o processo de formação do mercado de massa só se conforma com a chegada da televisão na década de 1950 e a expansão tanto do rádio quanto da TV em redes nacionais nos anos 1970. É a partir dos anos 1980 que o sistema de mídia brasileiro se consolida como indústria de massa, tendo a televisão como meio de comunicação central de entretenimento e informação. Neste processo, formaramse monopólios de grandes famílias, que passaram a controlar os principais veículos de comunicações no país. Atualmente, poucos grupos familiares comandam os setores de rádio e TV no Brasil. Os mais proeminentes são os Marinho (grupo Globo), os Saad (Bandeirantes), os Abravanel (SBT), os Civitas (grupo Abril até 2018), os Mesquitas (grupo O Estado de S. Paulo) e os Frias (grupo Folha de S.Paulo) (AZEVEDO, 2006).

Entretanto, importa ressaltar que os temas políticos não são prioridade para o público brasileiro: o assunto política está em 35 lugar entre os tipos de programas mais assistidos na TV (AZEVEDO, 2006). Esse quadro influencia diretamente no repertório do sistema midiático brasileiro. Observa-se baixa diversidade externa, ou seja, pouca heterogeneidade de informação e de opinião nos meios de comunicação de massa. Assim, tem-se pouca exposição aos cidadãos das distintas e conflitantes perspectivas políticas do Brasil. Tal fato conforma importante articulação entre o sistema de comunicação e os interesses políticos no Brasil (AZEVEDO, 2006).

Tendo sido visto, de modo geral e ligeiro, o panorama geral da estrutura dos meios de comunicação no Brasil, vejamos a localização da mídia impressa e dois de seus semanários neste contexto.

\section{Veja e CartaCapital no contexto midiático brasileiro}

De acordo com Azevedo (2006), o público alvo das principais mídias impressas brasileiras se concentra nas classes $\mathrm{A}$ e $\mathrm{B}$, devido à capacidade destes extratos em formar opiniões ${ }^{4}$. Com o objetivo de atingir tal público, tais publicações possuem linguagem específica, priorizando a cobertura opinativa política e econômica, junto com o 'jornalismo de informação’.

(...) [Estas publicações] compensam a baixa penetração nas camadas populares com a grande capacidade de produzir agendas, formatar questões e influenciar percepções e comportamentos tanto no âmbito político-governamental quanto no público em geral, este último através dos líderes de opinião ou através da repercussão da pauta dos jornais na televisão aberta (AZEVEDO, 2006, p. 8).

4 Para estudos sobre jornais que se concentram na classe C ver: De Figuereido (2010) e Paula (2012). 
Neste sentido, CartaCapital e Veja são amostra representativa do universo midiático dos semanários do país. Veja foi lançada em 1968 sob responsabilidade da Editora Abril. Faziam parte da direção editorial e de publicação inicial Vitor Civita, Roberto Civita e Mino Carta. A partir dos anos 1970, a Revista Veja consolidou sua apresentação e as seções se tornaram padrões em todas as edições seguintes. Nela, existe uma seção chamada de "Internacional” que, como o título deixa claro, trata dos assuntos internacionais da semana, normalmente envolvendo a temática da política externa, mas o tema também pode ser encontrado na seção que trata do governo e da economia. Também há seções para humor, entrevistas e editoriais. Seu público leitor se encontra nas classes média e alta (B e A) (VELASQUEZ; KUSHNIR, 2018). A maioria de seus leitores é do sexo masculino (cerca de 51\%) e o perfil dos mesmos, de acordo com a própria revista, é de empresários, empreendedores, representantes de órgãos públicos e formadores de opiniões (VEJA MÍDIA KIT, 2018).

A Revista CartaCapital foi criada em 1994 por Mino Carta, Bob Fernandes, Nelson Letaif e Wagner Careci. Inicialmente, a revista era mensal, passou a ser quinzenal, até se tornar semanal. O foco inicialmente era abordar questões econômicas, mas com o desenvolvimento da revista, questões políticas também passaram a fazer parte do conteúdo. Importa relatar que o Conselho Editorial de CartaCapital declarou apoio a Lula da Silva nas eleições presidenciais de 2002, causando intenso debate relativo a isenção ideológica dos meios de comunicação (POPINIGIS, 2018).

CartaCapital é dividida em seções, sendo o tema da política externa encontrado em “Nosso Mundo”. Ao contrário de Veja, as notícias referentes à política externa se encontram exclusivamente nesta seção, inserida como parte integrante da revista nos primeiros anos do governo Lula da Silva. Anteriormente, tal conteúdo podia ser encontrado nas seções 'Economia' ou 'Seu País'. A maioria dos leitores de CartaCapital também são do sexo masculino (cerca de 54\%), possuem mais de 35 anos e ensino superior completo. Assim como em Veja, a maioria dos leitores da Carta se concentra nas classes A e B (cerca de 88\%) (CARTACAPITAL MIDIA KIT, 2018, 2016).

Feita a localização dos dois semanários no mercado midiático brasileiro, vejamos a apresentação e análise dos dados colhidos em suas páginas.

\section{Apresentação e análise dos dados}

Esta seção está reservada para a apresentação dos dados coletados em Veja e CartaCapital durante os anos de 2003-2010 (primeiro e segundo mandatos de Luís Inácio Lula da Silva). No total, foram publicadas 414 edições de Veja e 406 de CartaCapital (excluindo-se edições especiais monotemáticas). Neste conjunto de 820 edições, foram selecionados, através de leitura sistemática, os artigos e reportagens explicitamente relacionados com a política externa e às relações internacionais do Brasil (incluídos temas econômicos internacionais, atuação em fóruns internacionais e questões diplomáticas brasileiras). Utilizando-se tal 
balizamento, foram encontrados 105 artigos em Veja e 115 na CartaCapital, perfazendo um total de 220 artigos analisados.

Veja apresentou maior quantidade de publicações nos anos de 2003, 2005 e 2010. A menor incidência de publicações ocorre entre meados de 2005 e o final de 2009. Tal fato deu-se pela decisão editorial de Veja enfatizar escândalos domésticos de corrupção (a partir de 2005, temos 'mensalão', mensalão 2, máfia dos sanguessugas, máfia dos juízes e casos de operações anticorrupção).

Em CartaCapital, o período de maior intensidade de publicação sobre o tema ocorre nos primeiros três anos do governo (destaque para o intervalo entre meados de 2004 até meados de 2005). Nos últimos anos do governo, principalmente a partir de março de 2009 até dezembro de 2010, houve diminuição e mesmo ausência das publicações, contabilizando apenas oito artigos durante este período. Assim, observou-se contraste entre o número mais alentado de publicações nos anos iniciais do governo e a quantidade inconstante dos anos finais. Fato explicado, provavelmente, como no caso de Veja, pela situação doméstica brasileira. No entanto, observa-se uma diferença entre os dois semanários: CartaCapital reservou edições quase exclusivas para discutir Política Exterior do Brasil. Veja, a despeito de possuir algumas edições com sessões especiais sobre a temática, não apresentou o volume e a ênfase de CartaCapital na abordagem e análise da formulação da política externa brasileira. Esse é o motivo pelo qual existem picos na quantidade de artigos publicados por CartaCapital como se nota no Gráfico 1.

Gráfico 1 - Quantidade de artigos PEB nas Revistas Veja e CartaCapital (2003-2010)

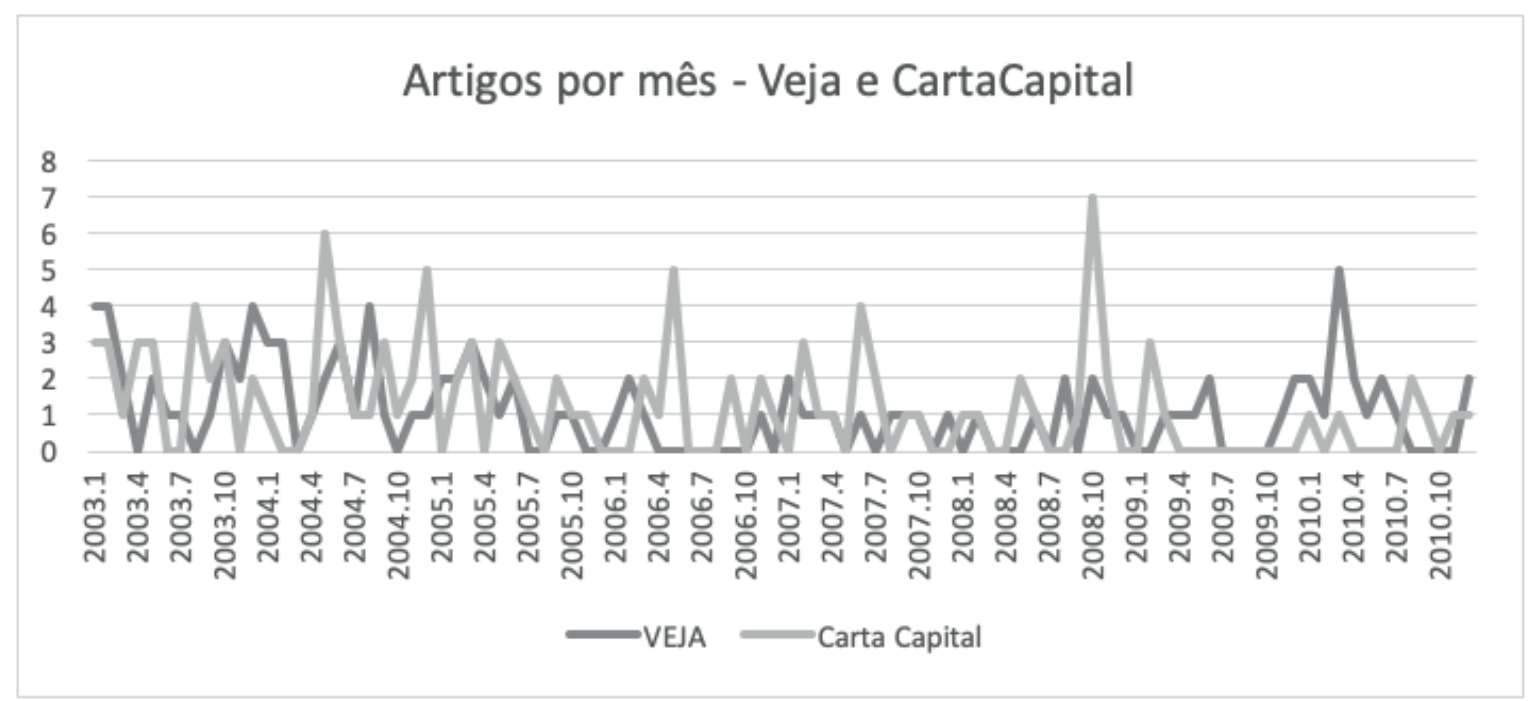

Fonte: elaboração dos autores. 


\section{Os principais temas das notícias}

\section{Veja}

Em 2003, Veja aborda temas como: a nomeação e atuação de diplomatas; a relação bilateral Brasil e Venezuela (enfatizando negativamente a amizade do presidente Lula da Silva com Hugo Chávez); as viagens de Lula a fóruns internacionais e a encontros de líderes mundiais (também com tom negativo); sobre a posição do Brasil a respeito das guerrilhas na América Latina; para diplomacia e o fato de algumas cidades brasileiras estarem despontando na economia mundial de forma independente; a relação brasileira e da elite intelectual do Brasil com Cuba; o‘fracasso’ de Lula na Europa; a atuação ‘fraca’ em uma reunião da ALCA; o deslize por 'elogiar a ditadura' em um encontro da ONU e as viagens de Lula da Silva à Ásia. Observe-se que todos os assuntos tratados apresentam viés negativo.

Em 2004, assuntos como migração, crises diplomáticas dos vistos, comportamentos constrangedores dos diplomatas, decisões questionáveis do Itamaraty e discursos 'retóricos' do presidente foram bem comuns. As visitas internacionais de Lula da Silva e sua amizade com 'ditadores' foram relatadas em tom irônico e repreensivo.

No ano de 2005, o primeiro semestre viu crescer o número de reportagens a respeito da política externa. Os assuntos foram, praticamente, os mesmo de 2004. Destacam-se o comportamento dos diplomatas e ações do Itamaraty, a possível relação do PT com as Farc, problemas com a Argentina, e a atuação do Brasil na ONU em busca do assento permanente no Conselho de Segurança. Tendência que se mantem até 2009.

Finalmente, em 2010, além de enfatizarem a relação do Brasil com o Haiti (devido ao terremoto) e a visita de Hillary Clinton ao país, as reportagens ainda chamam a atenção para a ‘amizade' de Lula da Silva com 'ditadores’ e ou ‘comunistas', como Hugo Chávez, Raul e Fidel Castro. Ainda, ressaltam-se, de modo negativo, as viagens internacionais de Lula da Silva e a abertura de embaixadas e consulados em diferentes países.

\section{CartaCapital}

Os artigos da revista CartaCapital, em 2003, focalizam, em sua maioria, a nova forma de atuação presidencial, as mudanças na relação com os EUA, a 'boa' atuação presidencial frente aos países da América Latina (enfoque para o papel de liderança da diplomacia brasileira e nos encontros com o líder venezuelano) e a atuação da diplomacia brasileira em fóruns internacionais (Davos, FMI, Mercosul e Alca). As relações mais reportadas nos primeiros anos do mandato Lula da Silva são aquelas referentes aos EUA, a China e a Venezuela (relações e acordos comerciais com os dois primeiros e relações diplomáticas com o último).

Nos demais anos, os assuntos tratados nas reportagens se assemelharam aos das reportagens de 2003, sendo acrescentados às temáticas de ocasião. Destacam-se os 
acontecimentos referentes à relação bilateral Brasil-EUA, as relações com países do oriente (crescimento das relações comerciais com a China), desempenho da diplomacia brasileira (destaque para a atuação do ex-presidente em fóruns internacionais como a ONU, OEA e o FMI). Ainda, observa-se destaque para a relação com a Venezuela, países emergentes e a formação dos BRICS.

\section{Comparação}

Quando comparados os dados (Gráfico 2), Veja publicou mais sobre diplomacia, citando ações de diplomatas, do Itamaraty e, principalmente, do ex-presidente e suas viagens (representando 65,7\% do total de reportagens sobre a política externa brasileira durante os oito anos de governo Lula). O segundo assunto foi sobre a atuação brasileira em fóruns internacionais (representando 23,8\% do total das reportagens da Veja). Ao contrário, o tema principal nas reportagens da revista CartaCapital foi sobre economia (cerca de 51,3\% do total das reportagens da revista durante os oito anos) e o segundo tema foi a diplomacia (32,7\% do total das notícias). Ressalta-se a diferença no foco das reportagens. Assim, enquanto Veja privilegia a diplomacia; CartaCapital, a economia. Veja enfatizou ininterruptamente as viagens internacionais de Lula da Silva durante seu mandato; CartaCapital optou for enfatizar as relações econômicas (principalmente com os EUA e a China).

Gráfico 2 - Temas das notícias nas revistas Veja e CartaCapital

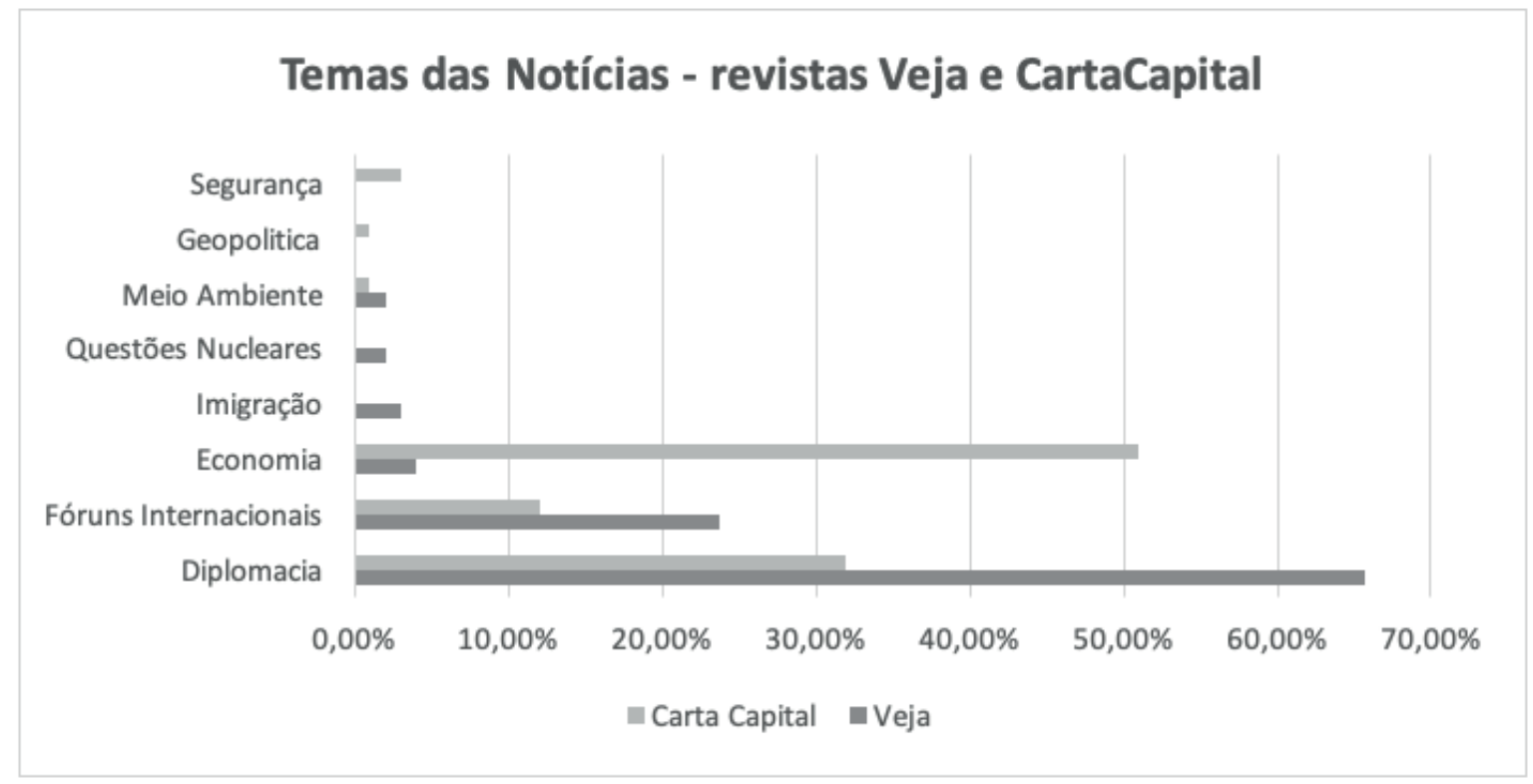

Fonte: elaboração dos autores. 


\section{A segmentação temática das notícias}

Como houve grande diversidade dos assuntos tratados nos artigos, pretende-se comparar os assuntos abordados pelas duas revistas. Neste sentido, os temas foram agrupados, para efeito analítico, entre relações multilaterais (Gráfico 3), fóruns internacionais (Gráfico 4) e relações bilaterais (Gráfico 5).

Gráfico 3 - Foco dos artigos quanto ao tema das relações multilaterais envolvendo o Brasil nas revistas Veja e CartaCapital

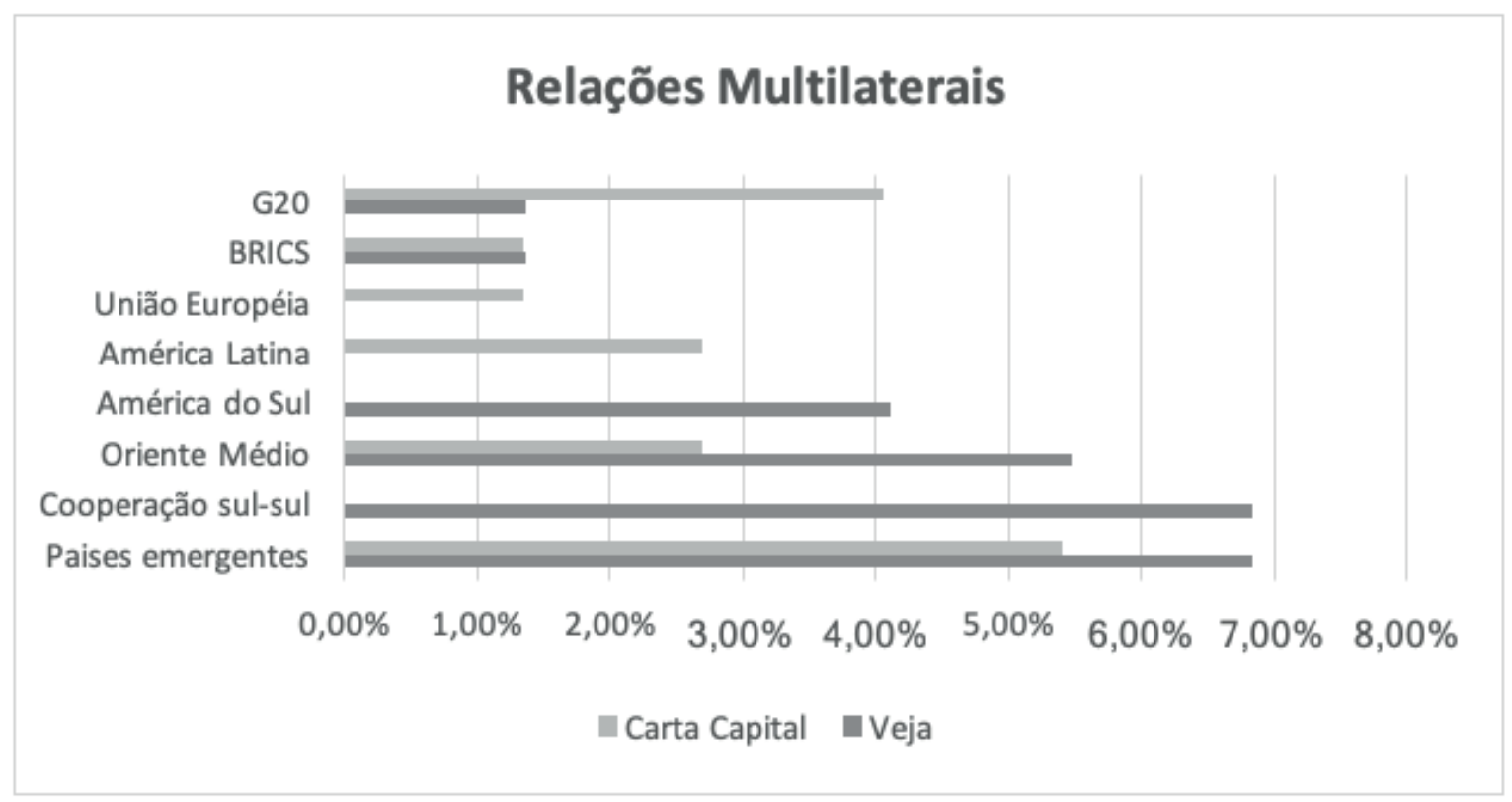

Fonte: elaboração dos autores.

Dessa comparação tem-se que a Veja focou mais nas relações multilaterais do que a CartaCapital, sendo o assunto principal da primeira: as relações com os países emergentes, cooperação sul-sul, relações com o Oriente Médio e relações na América do Sul. O contrário ocorre quando se trata dos fóruns internacionais: a CartaCapital publicou mais sobre esse assunto do que a Veja. A Carta abordou, além da OMC, Mercosul, ALCA, ONU, FMI todos também tratados pela Veja durante o período - Rodada Doha, OEA e o encontro de Davos. Sobre esse assunto também é relevante apontar que, enquanto a Veja focou em acontecimentos relacionados à OMC, a Carta focou no FMI. 
Gráfico 4 - Foco dos artigos quanto ao tema da atuação brasileira em fóruns internacionais nas revistas Veja e CartaCapital

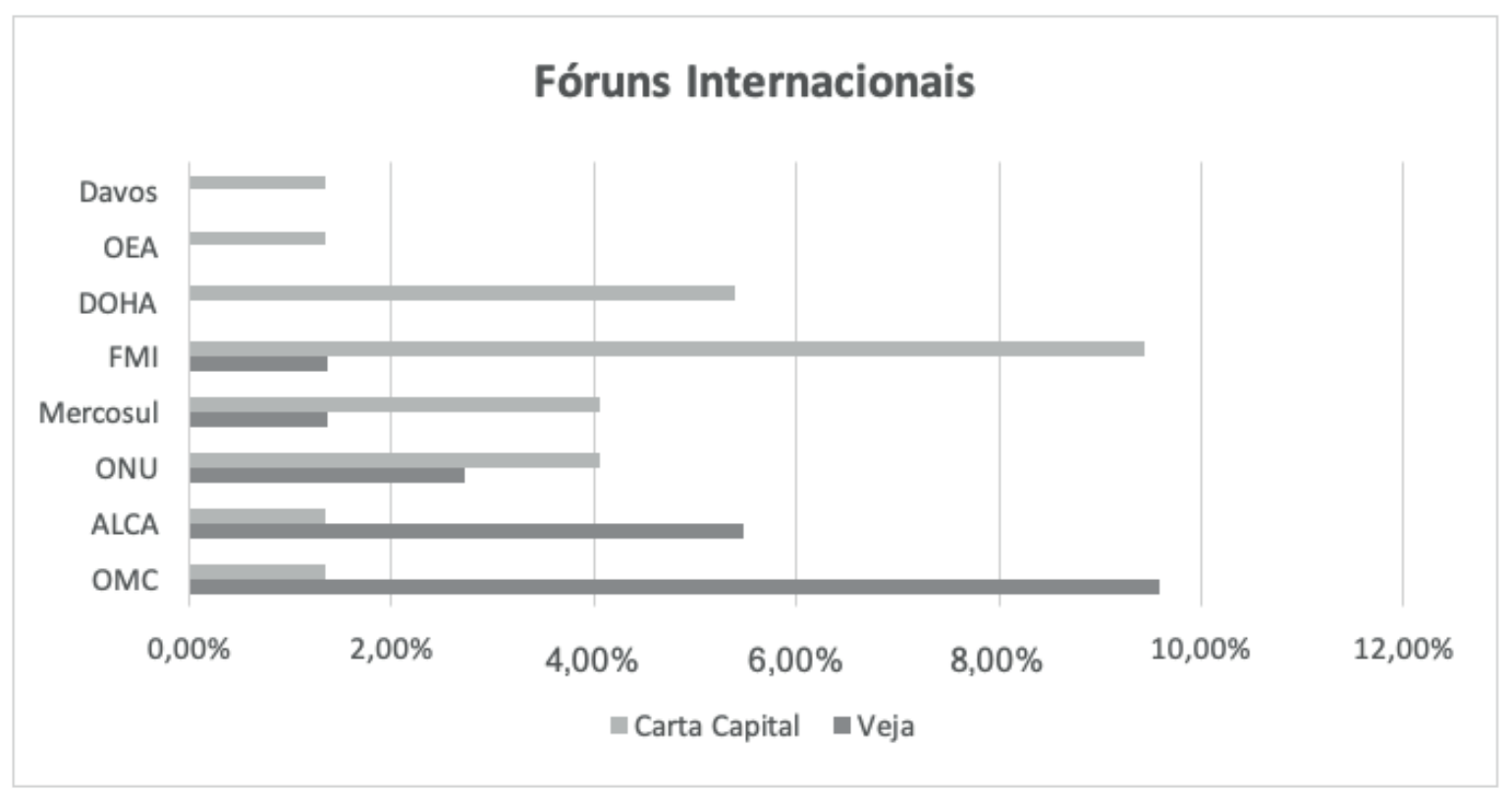

Fonte: elaboração dos autores.

Sobre as relações bilaterais, nota-se que a Veja optou por discutir as relações internacionais do Brasil por esta via: focando em um país específico citando mais países de forma individual do que a Carta. Também fica claro pelo Gráfico 5 que, mesmo a Carta não optando por notícias que abordassem mais relações bilaterais do que os outros modelos de relações categorizados aqui, ambas as revistas tiveram o maior número de suas publicações focadas nas relações entre Brasil e Estados Unidos. 
Gráfico 5 - Foco dos artigos quanto ao tema das relações bilaterais do Brasil nas revistas Veja e CartaCapital

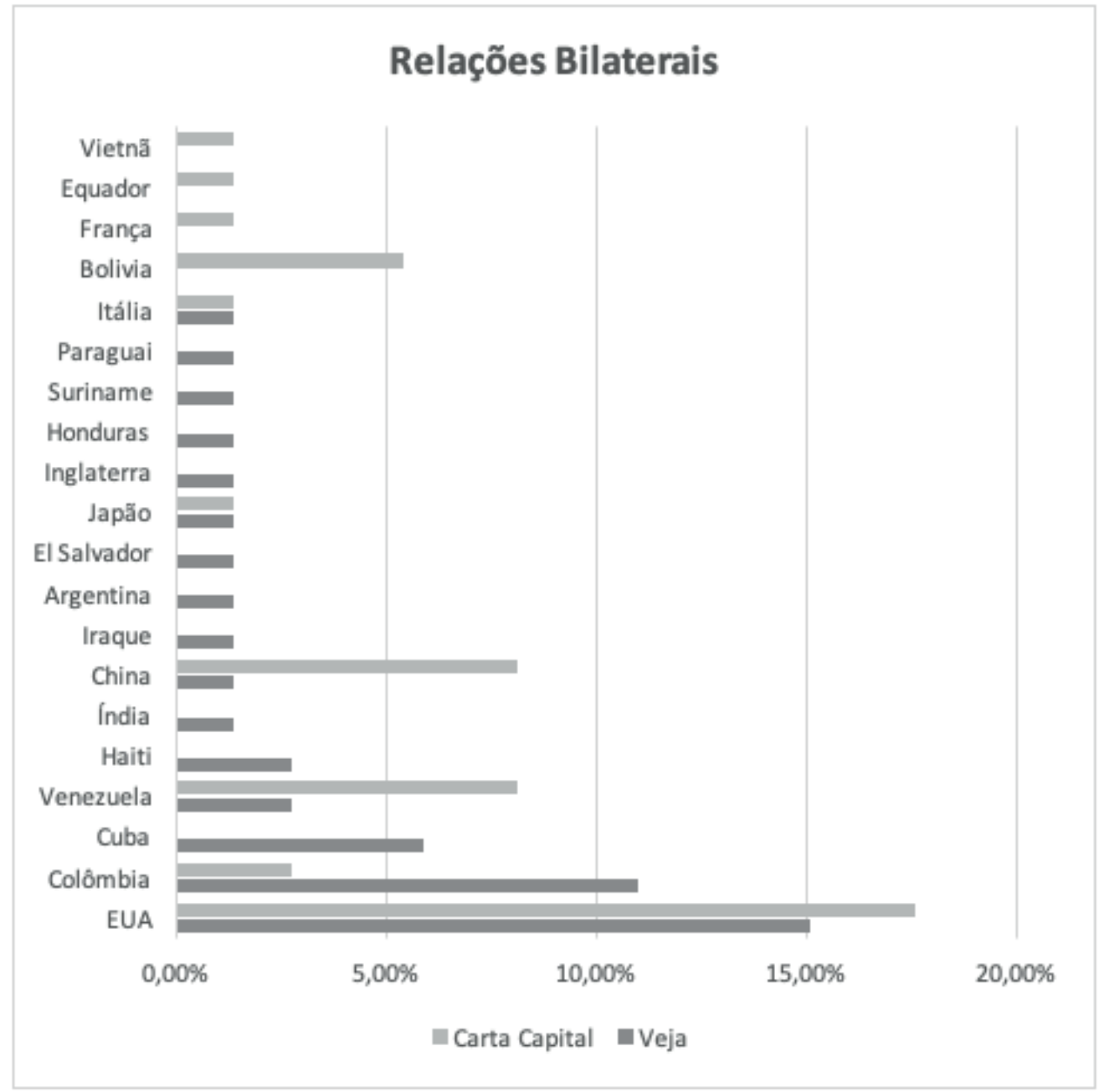

Fonte: elaboração dos autores.

\section{Viés das publicações}

Foi feita análise das publicações buscando-se seu teor negativo, positivo ou neutro sobre a PEB. Os considerados negativos explicitam, de forma cabal, negatividade com relação às ações e aos fatos apresentados. Os neutros informam as ações da PEB ou de outros países que afetam o Brasil, sendo impossível notar de forma explícita comentários contrários ou a favor de tais ações. As notícias positivas são aquelas que, de alguma forma, possuem comentários favoráveis às ações ou aos resultados para a política externa brasileira. 


\section{Veja}

Veja demonstra, praticamente na totalidade dos artigos, tom de incredulidade na política externa e de negatividade quanto às ações tomadas. A edição de número 1833, de 17 de dezembro de 2003 apresenta texto de Euripedes Alcântara que resume o teor dos comentários feitos a respeito do governo Lula da Silva (p. 43):

Duas coisas o governo Lula tem de ruim: a primeira é sua política social, que até hoje não se viu em que consiste. A outra é a diplomacia, que já deu perfeitamente para ver do que é feita (...) a ação política de Brasília no setor externo é apenas insignificante, quando não grotesca.

Outras reportagens comentam a respeito da política externa 'desastrosa' mascarada pelos escândalos de corrupção; as viagens de Lula da Silva ao exterior; a atuação 'fraca' frente a outros países emergentes em relação ao comércio exterior; conflitos dentro do Itamaraty quanto à política externa e atuação de diplomatas; questões sobre imigração; e a relação do Brasil com líderes considerados 'atrasados' ou 'contra a liberdade'.

Foram encontradas poucas reportagens com tom neutro ou positivo. Como exemplos, temos as visitas a países como o Reino Unido e aos EUA (tratados pelo semanário como 'mais desenvolvidos'). Mesmo assim, em algumas destas matérias, nota-se tom sarcástico ou crítico (viagens do ex-presidente à China e a atuação do Brasil dentro da OMC, por exemplo).

\section{CartaCapital}

Em CartaCapital, as reportagens, inicialmente, aparecem majoritariamente com tom positivo no que tange à PEB. Sobreleva-se a imagem de liderança de Lula da Silva. As publicações costumam ser iniciadas com contextos históricos (por vezes não muito breves) sobre o que se pretende tratar. Tais reportagens tendem relatar, além das ações da PEB, os fatos concernentes aos outros países ou fóruns nos quais o Brasil se enreda. Há reportagens que tratam os temas de modo abrangente e apontam detalhes das variáveis relativas aos temas da PEB.

Durante o último mandato, as reportagens trataram principalmente das relações com os EUA, com ênfase na ação brasileira em relação à crise que começou em 2008. Também se tratou da Bolívia, a relação do ex-presidente e do PT com as FARC e com os chamados países 'emergentes'. Nestes últimos anos a tendência foi de reportagens com tom mais negativo principalmente em se tratando da relação do Brasil com os EUA e a atuação do Brasil em fóruns internacionais, que na visão da revista havia caído e deixado de aproveitar muitas oportunidades. 


\section{Comparação}

Quanto à categorização sobre teor neutro, positivo ou contrário das reportagens (Gráfico 6), CartaCapital apresenta maioria de notícias de caráter neutro (60\%), seguidas de notícias negativas $(24,3 \%)$ e positivas (15,7\%). Veja publicou, em sua maioria, notícias contrárias ou negativas (43,8\%). As notícias consideradas neutras representam $(32,3 \%)$ e positivas (23,8\%).

Gráfico 6 - Teor positivo, negativou ou neutro das notícias das revistas Veja e CartaCapital

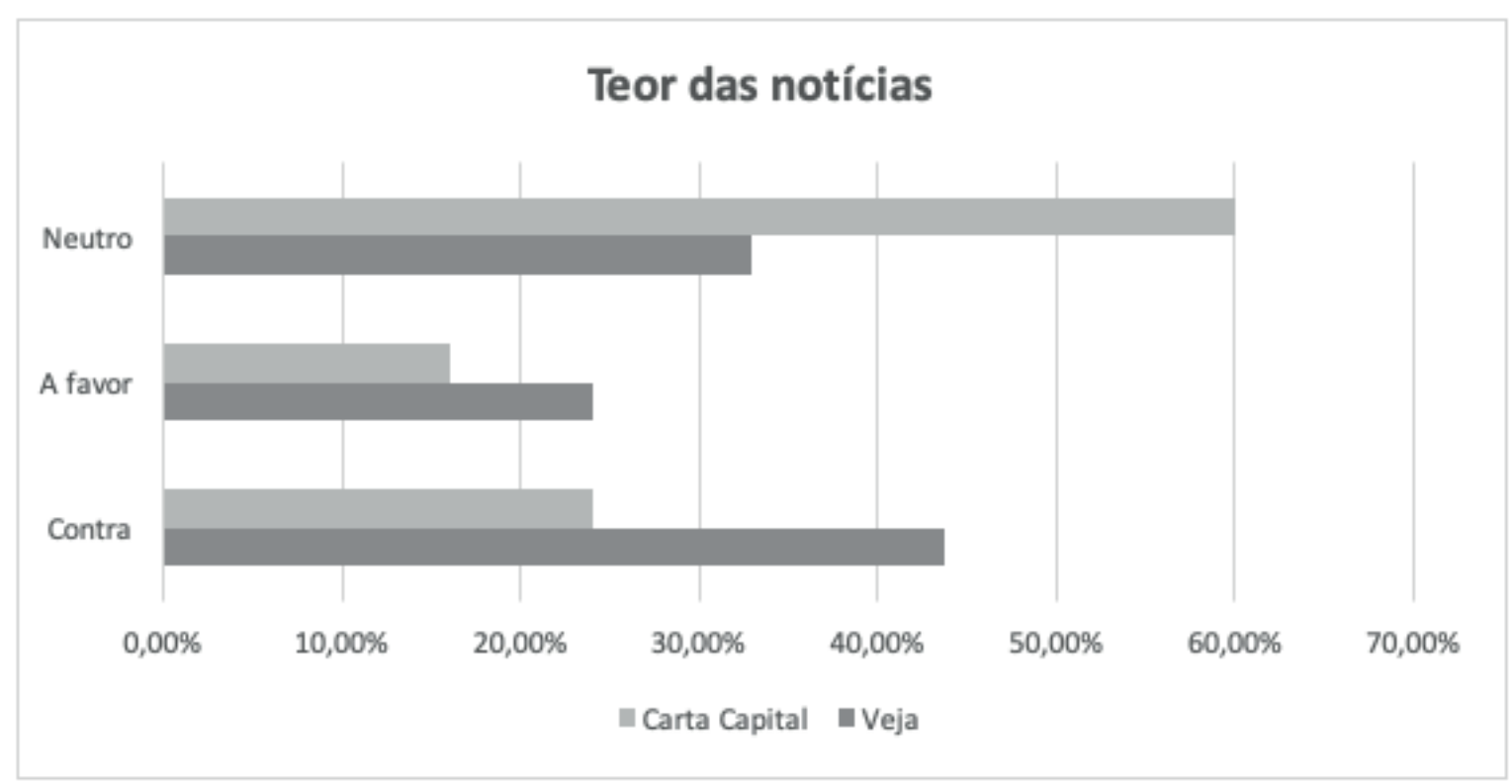

Fonte: elaboração dos autores.

Dois pontos devem ser destacados dessa comparação: primeiro, ambas as revistas tiveram pouca quantidade de artigos "positivos", o que pode não ter sido uma surpresa tendose conhecimento da posição editorial de Veja. Mas surpreende no caso de CartaCapital por seu explícito apoio ao candidato Lula da Silva, fato que a fez ser considerada publicação alinhada às pautas políticas da esquerda. De modo ilustrativo, os dados demonstram que CartaCapital, ao contrário de ser imagem oposta à Veja, demonstra política editorial mais complexa ao tratar do tema da política exterior do Brasil, não podendo ser caracterizada por descrições simplistas. Outro ponto a ser ressaltado foi a divergência entre a quantidade de artigos "negativos" e "neutros": em Veja os comentários negativos se relacionaram principalmente às ações diplomáticas do governo, enquanto em CartaCapital o foco dos comentários negativos refere-se, prioritariamente, às relações bilaterais com os EUA, principalmente no que tange à temática econômica. 


\section{A figura presidencial}

As citações diretas ao nome 'Lula da Silva' nas reportagens e sua atuação como expoente da PEB também foram analisadas e expostas no Gráfico 7. Elas ocorreram mais em Veja do que em CartaCapital. Veja apresenta Lula da Silva como o expoente na formulação e execução da política externa, sendo a ele creditados os feitos da política exterior no Brasil. CartaCapital entende a formulação e execução da política externa brasileira como liderada por um grupo, do qual o ex-presidente faz parte, mas inclui também ministros, diplomatas e grupos de interesse.

Gráfico 7 - Quantidade de notícias que citam a figura do ex-presidente Lula nas revistas Veja e CartaCapital

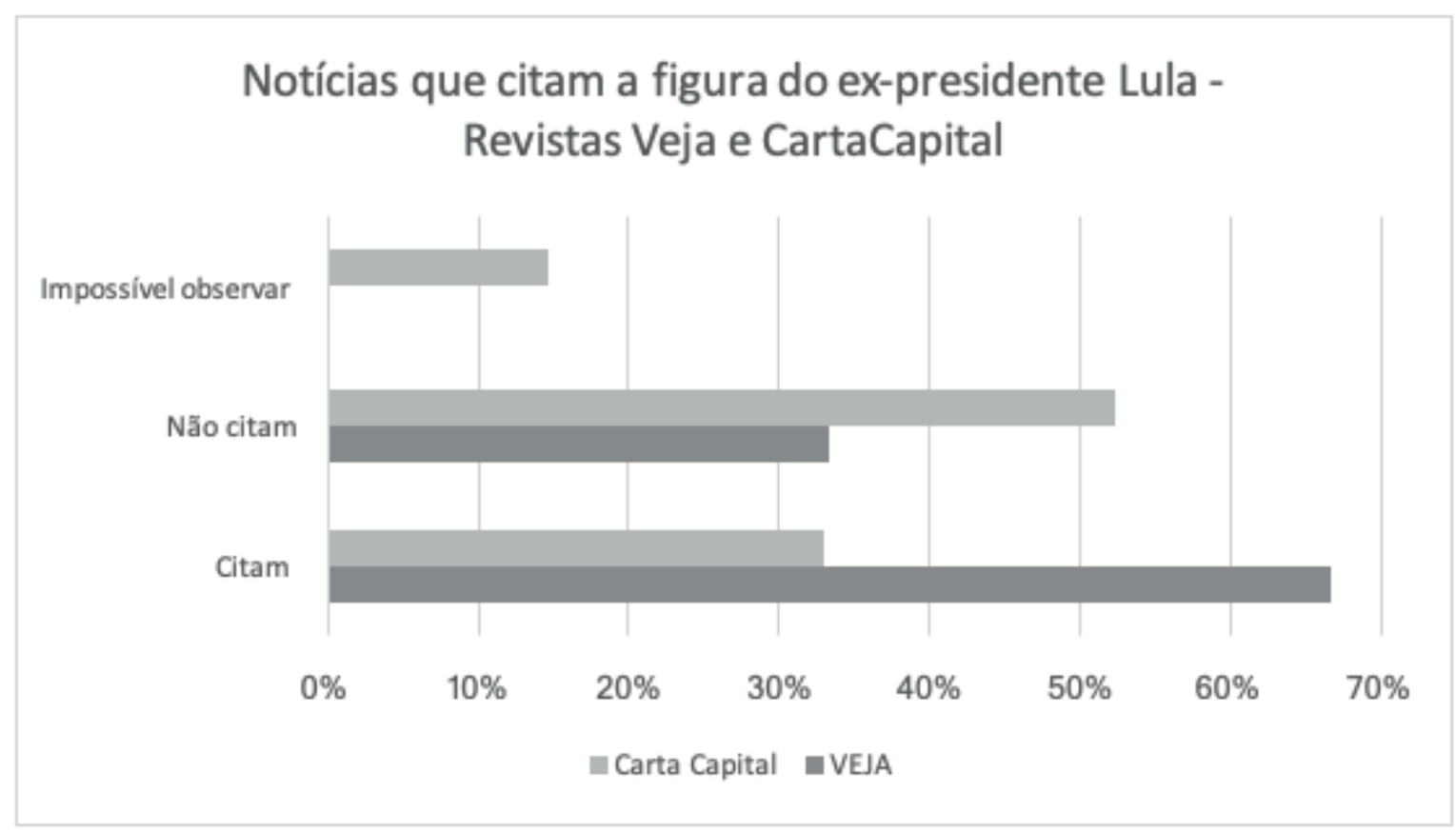

Fonte: elaboração dos autores.

Quando se analisa o subconjunto das notícias que citam a figura presidencial, percebe-se que Veja possui mais notícias contra a atuação presidencial, enquanto em CartaCapital predominam notícias neutras (Gráfico 8). Em Veja, os comentários negativos se relacionaram principalmente às ações diplomáticas do governo, enquanto na Carta 0 foco dos comentários negativos foi a relação brasileira com os EUA, principalmente no que tange à temática econômica. 
Gráfico 8 - Teor das notícias que citam a figura do ex-presidente Lula nas revistas Veja e CartaCapital

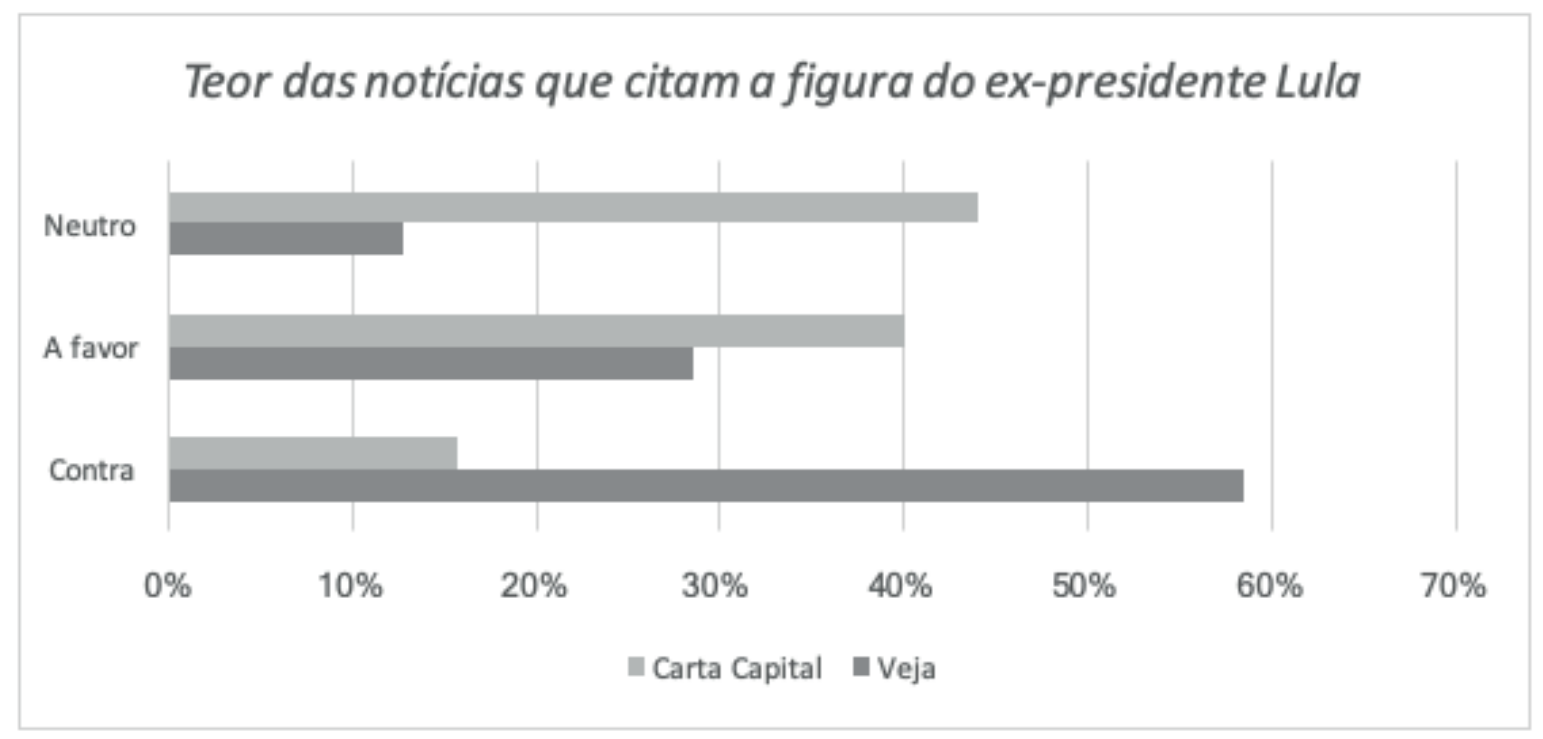

Fonte: elaboração dos autores.

\section{Considerações finais}

O presente trabalho demonstrou a diferença na cobertura da política externa brasileira (PEB) em dois semanários brasileiros durante a gestão de Luís Inácio Lula da Silva (20032010). Para tanto, analisou de forma qualitativa e quantitativa tal temática nas páginas de VEJA e CartaCapital. Discutiu, brevemente, em sintonia com as teorias da Análise de Política Externa (APE), como os meios de comunicação podem ser incluídos no quadro de variáveis que compõem o complexo processo de tomada decisão política. Neste sentido, explicitou-se que os meios de comunicação podem adquirir algum grau de influência nos centros de decisão política, mesmo que sua intensidade seja motivo de debate.

Identificou-se que diferentes linhas editoriais expressam distintas visões políticas. No entanto, apesar de tal variável não ter sido aprofundada neste estudo, pode-se inferir que os grupos de comunicação, sendo empresas vinculadas a grupos de interesses com agendas específicas, tendem a adotar linhas editoriais condizentes com os valores dos segmentos sociais que representam. Neste sentido, testou-se a hipótese de que as distintas linhas editoriais de Veja e CartaCapital fariam divergir, quantitativa e qualitativamente, a cobertura jornalística sobre a temática da PEB no período compreendido entre 2003 e 2010.

Liminarmente, observou-se o diminuto ‘mercado' para ‘consumir' notícias referentes à política externa, uma vez que pequena parcela nos segmentos A e B da população brasileira é leitora dos semanários postos em análise neste trabalho. A despeito deste fato, os resultados 
encontrados apontam divergências no tratamento para a mesma temática, fato que comprova, parcialmente, a hipótese geral levantada.

Ao abordar o tema da PEB, Veja publicou mais sobre diplomacia, enquanto CartaCapital privilegiou os temas econômicos. De modo mais específico, observou-se contraste nas citações ao ex-presidente Lula da Silva. Veja apresentou o ex-presidente como o ator mais relevante na formulação e execução da política externa, sendo a ele vinculados e creditados os resultados das ações neste campo da ação política. CartaCapital entendeu a formulação e execução da PEB como processo liderado por determinado grupo, do qual o ex-presidente faz parte. Mas também incluiu neste processo ministros, diplomatas e outros grupos de interesse.

Veja publicou, em sua maioria, notícias negativas (58,5\%) em relação a Lula da Silva. CartaCapital, diferentemente, apresentou maioria neutra (44,7\%). O que demonstra que CartaCapital não estava, pelo menos no recorte histórico observado, totalmente oposta à Veja no espectro político quanto a abordagem da política externa. Quanto à segmentação temática ambas as revistas discutiram a PEB, em sua maioria, através das relações bilaterais e tiveram o maior número de suas publicações abordando as relações entre Brasil e Estados Unidos (mesmo que com abordagens distintas).

Neste ponto das considerações finais, a despeito de não ser o objetivo precípuo deste trabalho, reserva-se espaço para apontamentos finais sobre a relação entre opinião pública, meios de comunicação e política externa. O objetivo é apresentar literatura mais recente sobre o tema e apontar possíveis conexões entre os achados do trabalho e seus desdobramentos para a PEB. Segundo Baum e Potter (2008, 2019), o descaso que se observou relativo à influência da opinião pública nos estudos de política externa explica-se pela crença, por parte dos tomadores de decisão e atores políticos, de que essa opinião era volátil e incoerente. No entanto, note-se que, já no século XVI, Maquiavel julgava que a opinião seria capaz de influenciar os governantes. Assim, o poder torna-se interessado em manipular notícias em benefício próprio (WATT, 1986). Portanto, nas últimas décadas, adensam estudos que buscam alimentar o debate teórico sobre tal temática.

Baum e Potter (2008) consideram que o engajamento do público nos assuntos de política externa seria proporcional ao nível de informação retida. Também devemos levar em conta que, em sua maioria, a posse dos meios de comunicação pertence à elite. Neste sentido, podemos pensar que eles atuam intimamente com a opinião pública que, nas sociedades democráticas liberais, pode legitimar o poder político e influir na condução da política externa dos Governos. Seguindo tal lógica, os meios de comunicação seriam atores estratégicos discretos, cujas informações passam a ter o potencial de causar comoção pública através do engajamento em questões domésticas e de política externa. Neste aspecto, o uso da informação opera em duplo sentido: informa aos líderes as necessidades populares e poderá contribuir para minar a legitimidade dos governantes (NAVEH, 2002). De resto, os autores realçam que a literatura mais recente tem enfatizado a interdependência entre opinião pública, meios de comunicação e política externa, uma vez que “dar atenção exclusiva a 
um ou dois destes atores poderia distorcer as previsões teóricas e os achados empíricos” (BAUM; POTTER, 2008, p. 40).

Assim, os meios de comunicação, a opinião pública e os formuladores de políticas dialogam. Embora haja escolas de pensamentos divergentes no grau e na forma, essa interação é e tem sido objeto de discussão e investigação empírica. Conforme já citado, o subcampo da APE seria singularmente mais receptivo à responsividade dos tomadores de decisão quando se trata da opinião (HUDSON, 2014). Em concordância com tais preceitos, acreditamos que os achados desta pesquisa possam indicar esta mútua interação de fatores ao inserirmos os meios de comunicação no processo político brasileiro a expressar sentimentos relativos aos governantes que, transbordados, e em interação com a opinião pública, possam influenciar a formulação da PEB. Para tanto, vejamos, brevemente, aspectos da formulação desta política nacional.

No caso brasileiro, há fatores históricos que levaram a um dito ‘insulamento’ do processo de gestação da PEB. Dentre eles estão elementos estruturais como a Constituição do Brasil de 1988, a introversão nos processos políticos e econômicos, o caráter não conflitivo da PEB e a precoce profissionalização da corporação diplomáticas (CHEIBUB, 1985, FARIA, 2008). Tais fatores, aliados ao “presidencialismo de coalizão”, reiteram o papel central do poder Executivo tanto nas discussões de política externa, quanto na aceitação por parte do Congresso dos acordos internacionais (FIGUEIREDO; LIMONGI, 1999). No entanto, nova conjuntura política e social, manifesta pelo processo de recondução dos civis ao poder (1985) e confecção da Constituição Federal de 1988 teria, gradualmente, aumentado a politização da PEB através da maior participação do país em espaços multilaterais, do processo internacional de globalização, do incentivo a liberalização econômica e da "revolução" dos meios de comunicação. Decorre, então, o aumentado da participação da sociedade brasileira no plano internacional. Haveria contraste com as tradicionais bases encarregadas da tomada de decisão em assuntos externos (FARIA, 2008).

Quanto ao sistema de mídia no Brasil, Azevedo (2006) argumenta que este ainda guarda características históricas com concentração em grupos familiares e um direcionamento que prioriza as elites. Em sua taxonomia, tal sistema teria caraterísticas do modelo pluralista polarizado. Entretanto, é importante salientar que a influência da mídia vai muito além do público desinteressado, tendo impacto sobre atores distintos, como líderes governamentais e grupos de interesse que demandam políticas. Assim, pode-se pensar em mecanismos causais implícitos pelos quais, em princípio, a mídia pressiona, diretamente ou através da opinião pública, os líderes a tomarem posição sobre problemas negligenciados anteriormente. Ainda, poderiam estabelecer agendas de política externa a serem abordadas pelos governos.

Neste sentido, pode-se argumentar que o ‘debate’ expresso nas páginas de Veja e CartaCapital refletem momento político do Brasil no qual a temática da PEB compõe quadro de interrelação entre a opinião pública, os meios de comunicação e os formuladores da política exterior. Mas, como demostrar a causalidade desta relação não é o objetivo deste trabalho, deixamos a sugestão para futuro desenvolvimento desta importante agenda de 
pesquisa. Assim, este estudo também pretende ser modesto incentivo para futuras e mais profundas análises da influência dos meios de comunicação nos processos políticos em geral e para a Política Exterior em particular.

\section{Referências}

AZEVEDO, F. A. Mídia e democracia no Brasil: relações entre o sistema de mídia e o sistema político. Opinião Pública, v. 12, n. 1, p. 88-113, 2006.

BAUM, M. A.; POTTER, P. B. K. The Relationships Between Mass Media, Public Opinion, and Foreign Policy: Toward a Theoretical Synthesis. Annu. Rev. Polit. Sci. n. 11, p. 39-65, 2008.

BAUM, M. A.; POTTER, P. B. K. Media, Public Opinion, and Foreign Policy in the Age of Social Media. The Journal of Politics, 2019.

BURITY, C. R. T. A influência da mídia nas Relações Internacionais: um estudo teórico a partir do conceito de Diplomacia Midiática. Contemporânea (Título não-corrente), v. 11, n. 1, 2013.

CARTACAPITAL MIDIA KIT 2018. Disponível em: https://www.cartacapital.com.br/anuncie/media-kitmaio-2018. Acesso em: 26 jul. 2018.

CARTACAPITAL MIDIA KIT 2016. Disponível em: https://www.editoraconfianca.com.br/formatos_html/ assets/midia-kit-cartacapital---2016.pdf. Acesso em: 26 jul. 2018.

CASARÕES, G. S. P. A mídia e a política externa no Brasil de Lula. Austral: Revista Brasileira de Estratégia e Relações Internacionais, v. 1, n. 2, p. 211-236, 2012.

CHEIBUB, Z. B. Diplomacia e construção institucional: o Itamaraty em uma perspectiva histórica. Dados, Revista de Ciências Sociais, Rio de Janeiro, v. 28, n. 1, p. 113-131, 1985.

CHOMSKY, N.; HERMAN, E. A propaganda model. Manufacturing Consent: the Political Economy of the Mass Media. $2^{\text {a }}$ ed. New York: Pantheon Books, p. 1-35, 2002.

COHEN, B. C. Mass communication and foreign policy. Domestic sources of foreign policy, p. 195-212, 1967.

DE FIGUEIREDO, P. Os Novos Jornais Populares: análise de uma tendência. In: XV CONGRESSO DE CIÊNCIAS DA COMUNICAÇÃO NA REGIÃO SUDESTE. Vitória, Espírito Santo. 13 a 15 de maio de 2010. Anais.... Disponível em: http://www.intercom.org.br/papers/regionais/sudeste2010/resumos/R19-0183-1. pdf. Acesso em: 21 ago. 2020.

FARIA, C. A. P. de. Opinião pública e política externa: insulamento, politização e reforma na produção da política exterior do Brasil. Revista Brasileira de Política Internacional. Brasília: UnB, v. 51, n. 2, 2008.

FIGUEIREDO, A. C.; LIMONGI, F. Executivo e Legislativo na nova ordem constitucional. Rio de Janeiro: FGV, 1999.

HUDSON, V. M. Foreign Policy Analysis: Actor-Specific Theory and the Ground of International Relations. Foreign Policy Analysis. v. 1, n. 1, p. 1-30, 2005.

HALLIN D., C. The Uncensored War, The Media and Vietnam. 1986.

HERMAN, E.; CHOMSKY, N. The manufacture of consent. New York: Pantheon, 1988.

HILL, C. The constituencies of foreign policy. In: HILL, C. The changing politics of foreign policy. Palgrave, 2003.

KEOHANE, R. O.; NYE, J. S. Power and interdependence. 1977. 
LESSA, M.; GAVIÃO, L. Política externa, mídia e propaganda nos governos Lula da Silva (2003-2010). In: FREIXO, A. de et al. (Orgs.). A política externa brasileira na Era Lula: um balanço. Rio de Janeiro: Apicuri, 2011.

MARINUCCI, R. B. Relações Internacionais e mídia. Universitas: Relações Internacionais, v. 6, n. 1, 2009. MIGUEL, L. F. Retrato de uma ausência: a mídia nos relatos da história política do Brasil. Revista Brasileira de História, v. 20, n. 39, p. 191-199, 2000.

NAVEH, C. "The Role of the Media in Foreign Policy Decision-Making: A Theoretical Framework”. Conflict \& communication, v. 1, n. 2, 2002.

NOGUEIRA, S. Reflexões sobre o papel da mídia na construção do nationess: os casos da Telesur e da AlJazeera. Carta Internacional, v. 7, n. 2, p. 127-148, 2012.

ROBISON, P. The role of media and public opinion. In: SMITH, S.; HADFIELD, A.; DUNNE, T. Foreign Policy - Theories, actors, cases. Oxford University Press, USA; 2008.

ROBINSON, P. Theorizing the influence of media on world politics: Models of media influence on foreign policy. European Journal of Communication 16, no. 4., 523-544, 2001.

SODRÉ, N. W. História da imprensa no Brasil. Mauad Editora Ltda, 1998.

PAULA, G. S. N. de. A classe $\mathbf{C}$ vai às bancas: a ascensão dos tablóides populares no Brasil. 2012. 164f. Dissertação (Mestrado em Jornalismo). Universidade Federal de Santa Catarina, Centro de Comunicação e Expressão.

POPINIGIS, F. Dicionário Histórico-Biográfico Brasileiro/CPDOC/FGV. Verbete Carta Capital. Disponível em: http://www.fgv.br/cpdoc/acervo/dicionarios/verbete-tematico/carta-capital. Acesso em: 26 jul. 2018.

RADENOVIC, M. R. Opinião Pública Mundial: Formar ou Manipular. Revista PRISMA. COM, n. 2, 2010.

SHAW, E. F. Agenda-setting and mass communication theory. Gazette (Leiden, Netherlands), v. 25, n. 2, p. 96-105, 1979.

SOROKA, S. N. Media, public opinion, and foreign policy. Harvard International Journal of Press/ Politics, v. 8, n. 1, p. 27-48, 2003.

SCHULZ, K. Foreign Policy Involvement Matters: Towards an Analytical Framework Examining the Role of the Media in the Making of Foreign Policy. Global Media Journal: German Edition, v. 3, n. 1, Spring/ Summer 2013.

VEJA MIDIA KIT 2018. Disponível em: http://publiabril.abril.com.br/midia_kits?brand=Veja. Acesso em: 26 jul. 2018.

VELASQUEZ, M. C. C.; KUSHNIR, B. Dicionário Histórico-Biográfico Brasileiro/CPDOC/FGV. Verbete VEJA. Disponível em: http://www.fgv.br/cpdoc/acervo/dicionarios/verbete-tematico/veja. Acesso em: 26 jul. 2018.

WATT, D. C. Opinião pública. In: SILVA, B. (Coord.). Dicionário de Ciências Sociais. Rio de Janeiro: FGV, 1986.

\section{Túlio Sérgio Henriques Ferreira}

Graduado em Jornalismo pela Pontifícia Universidade Católica de Minas Gerais (1991) e História pela Universidade Federal de Minas Gerais (1997). Especialista (2002), Mestre (2006) e Doutor 
em Relações Internacionais pela UnB (2012). Pós-doutorado/Visiting Professor Brown University (2018-2019). Integrante do Grupo de Pesquisa MOPRI - Mídia e Opinião Pública nas Relações Internacionais, da Universidade Estadual da Paraíba (UEPB), certificado pelo CNPq. E-mail: tulioferreira@gmail.com.

\section{Ester Almeida Carneiro da Cunha}

Mestranda do Programa de Pós-Graduação em Relações Internacionais do Instituto de Relações Internacionais da Universidade de São Paulo (USP). Bacharel em Relações Internacionais pela Universidade Federal da Paraíba (UFPB). Pesquisadora bolsista pela Universidade de Salamanca (Espanha). E-mail: ester.almeida.cunha@gmail.com.

Recebido em: 04.06.2019

Aprovado em: 02.09.2020 